\title{
Perception of Clinicians and Diabetic Patients on the Importance of Postprandial Glucose Control and Diabetes Education Status: A Cross Sectional Survey
}

\author{
Ji Hun Choi ${ }^{1}$, Cheol Young Park ${ }^{1}$, Bong Soo Cha ${ }^{2}$, In Joo Kim³ ${ }^{3}$ Tae Sun Park ${ }^{4}$, Joong Yeol Park ${ }^{5}$, Kyung Soo Park \\ Kun Ho Yoon ${ }^{7}$, In Kyu Lee ${ }^{8}$, Sung Woo Park ${ }^{1}$ \\ ${ }^{1}$ Division of Endocrinology \& Metabolism, Department of Internal Medicine, Kangbuk Samsung Hospital, Sungkyunkwan University School of Medicine, \\ Seoul, \\ ${ }^{2}$ Department of Internal Medicine, Yonsei University College of Medicine, Seoul, \\ ${ }^{3}$ Department of Internal Medicine, Pusan National University School of Medicine, Busan, \\ ${ }^{4}$ Department of Internal Medicine, Chonbuk National University Hospital, Jeonju, \\ ${ }^{5}$ Department of Internal Medicine, University of Ulsan College of Medicine, Seoul, \\ ${ }^{6}$ Department of Internal Medicine, Seoul National University College of Medicine, Seoul, \\ ${ }^{7}$ Department of Internal Medicine, The Catholic University of Korea College of Medicine, Seoul, \\ ${ }^{8}$ Department of Internal Medicine, WCU Program, Kyungpook National University School of Medicine, Daegu, Korea
}

Background: Recent studies have shown the importance of postprandial glucose (PPG) in the development of diabetes complications. This study was conducted in order to survey the perceptions of clinicians and diabetic patients with respect to PPG management and the current status of diabetes education.

Methods: This was a cross-sectional study involving face-to-face interviews and an open questionnaire survey conducted in Korea. A total of 300 patients and 130 clinicians completed questionnaires, which included current education status, self monitoring of blood glucose (SMBG), criteria of diagnosis and management, and perceptions relating to PPG management.

Results: While there was a significantly higher perceived need for diabetes education, the sufficiency of the current education was considered to be severely lacking. Fasting plasma glucose (FPG), PPG, and glycosylated hemoglobin (HbA1c) were all important considerations for clinicians when making a diagnosis of diabetes, although PPG was considered less important than FPG or HbAlc in the treatment of diabetes. Most clinicians and patients were aware of the importance of PPG, but actual education on the importance of PPG was not actively being delivered.

Conclusion: Our study showed that the current status of diabetes education is insufficient to meet the needs of the Korean population. A considerable gap was found to exist between awareness and what was actually taught in the current education program in regard to the importance of PPG. These results suggest that clinicians need to be more active in patient education, especially in regard to the importance of PPG.

Keywords: Diabetes education; Diabetes mellitus, type 2; Perception; Postprandial glucose

\section{INTRODUCTION}

Diabetes is a chronic illness that requires continual medical care and patient self-management in order to reduce the risk of long-term complications [1]. Assessing glycemic control status has always been important in the management of diabetes. Selfmonitoring of blood glucose (SMBG) and glycosylated hemoglobin (HbA1c) testing first became available in the 1970s and

\footnotetext{
Corresponding author: Sung Woo Park

Division of Endocrinology \& Metabolism, Department of Internal Medicine, Kangbuk Samsung Hospital, Sungkyunkwan University School of Medicine, 29 Saemunan-ro, Jongno-gu, Seoul 110-746, Korea

E-mail: sungwoo0913.park@samsung.com

Received: Dec. 13, 2010; Accepted: Nov. 16, 2011
}

This is an Open Access article distributed under the terms of the Creative Commons Attribution Non-Commercial License (http://creativecommons.org/licenses/by-nc/3.0/) which permits unrestricted non-commercial use, distribution, and reproduction in any medium, provided the original work is properly cited. 
1980s. However, HbA1c level does not provide a real-time glucose profile of individual hyperglycemic or hypoglycemic excursions. On the other hand, SMBG reveals immediate hourto-hour blood glucose data. The real-time information provided by SMBG represents an important adjunct to HbAlc level because it can reveal fasting and postprandial hyperglycemia and allows for the detection of glycemic excursions and hypoglycemia [2].

Among the many interventions recognized for improving outcomes for those with diabetes, the importance of therapies that are tailored to achieve specific glycemic targets is increasingly apparent. Traditionally, interventions have largely focused on optimizing the overall glycemic control as assessed by the HbAlc and fasting plasma glucose (FPG) values [3]. However, in recent years, there are mounting evidences that highlight the importance of targeting postprandial hyperglycemia and demonstrate a significant relationship between elevated postprandial glucose (PPG) and the risk of diabetes complications [4-6]. In addition, previous studies conducted in Europe [7,8], the USA [9], and Asia [10] suggest that PPG is a better predictor of cardiovascular and all-cause mortality than fasting glucose both in people with diabetes and with pre-diabetic impaired glucose tolerance. Despite the importance of PPG, there is a considerable lack of public awareness regarding the importance of controlling PPG.

Effective self-management and diabetes education are important factors in successful treatment. There is a need to develop an educational program to effectively manage patients with diabetes. Additionally, the communication between clinicians and patients/guardians and information delivery are greatly emphasized [11]. However, there is currently little data on the differences in ways in which clinicians and type 2 diabetes (T2DM) patients recognize the importance of PPG control and patient education status. Our survey sought to evaluate the perceptions of clinicians and patients on the status of diabetes education and the importance of PPG in order to help develop an adequate patient education program for the effective management of diabetes, with particular focus on PPG.

\section{METHODS}

This was a cross-sectional study involving face-to-face interviews and a questionnaire survey that was conducted in Korea between October 22nd and November 19th, 2009 by Synovate Healthcare Korea (Seoul, Korea).

\section{Sampling procedure}

The study included 300 T2DM patients and 130 clinicians. There were 257 endocrinologists serving general hospitals (GH) and 3,279 internists serving in local clinics (CL) throughout Korea based on the 2004 Korean Medical Data Index (KMDI). With the smallest sample size $(n=30)$ possible for normal distribution, 30 endocrinologists practicing at a GH and 100 internists practicing in CL that were seeing $\geq 50 \mathrm{~T} 2 \mathrm{DM}$ patients in an average week were included in our study. Considering that clinicians in the same hospital would have similar patient groups and treatment patterns, we selected a single clinician from each hospital and clinic.

The sample size $(n=300)$ of diabetic patients that were between the ages of 40 and 65 years and that have had at least 6 months of treatment was determined to enable us to take a $95 \%$ confidence interval with a standard error of $5.44 \%$ based on the 7,775 diabetic patients that had participated in the 2001 Korean National Health and Nutrition Examination Survey (KNHANES). The subjects were quota assigned according to age, gender and area with the smallest sample size $(n=30)$ for stratified analysis. Of these patients, $236(78.7 \%)$ were treated in a primary care facility, and the remainder were treated in a secondary care facility. Participants were randomly recruited for participation in this study, regardless of the therapeutic relatedness between the clinicians and the diabetic patients who responded to the survey.

\section{Interview survey and survey tools}

Data were collected through quantitative, one-on-one, in-person interviews using a structured questionnaire. Two surveys were used: one tailored to T2DM patients and the other specific to the clinicians. The clinician questionnaire included ten questions related to demographics and patient potential and 33 questions related to the "diabetes patient education status." The patient questionnaire included 13 questions related to demographics and 36 questions related to "diabetes patient education status," which were divided into four parts: current education status, self monitoring of blood glucose (SMBG), criteria of diagnosis and management, and perception of PPG management. The surveys took approximately 30 minutes to complete.

\section{Data analysis}

All interviews were coded using the software program SurveyCraft, and the data were analyzed using SPSS for Windows 
version 17.0 (SPSS Inc., Chicago, IL, USA). Continuous variables were reported as mean \pm standard deviation, and categorical variables were reported as number and percentage. Chisquare test, two sample $t$-test and repeated measures ANOVA were used for data analysis. A $P$ value of less than 0.05 was considered to be statistically significant.

\section{RESULTS}

\section{Subject characteristics}

The mean age of the 300 patients was $52 \pm 7$ years, and the mean age at which they were diagnosed with diabetes was $46.2 \pm 6.6$ years. Ninety-four percent of the patients were being treated with only oral hypoglycemic agent (OHA) therapy. Subjects in the 60- to 65-year-old patient group and patients with prescriptions from a GH endocrinologist reported that they more frequently used insulin combined with OHA or insulin monotherapy compared with younger patients ( $13.3 \%$ vs. $3.8 \%$; $P=0.004)$ or patients with drug prescriptions from an internist at a $\mathrm{CL}$ (7.9\% vs. $5.1 \%$; $P=0.385$ ).

Clinicians who participated in this survey reported that $67 \%$ of their T2DM patients were treated with only OHA therapy, and $18 \%$ were treated with a combination of OHA and insulin therapy. Among the patients who were treated with only OHA, $52 \%$ were on two types of OHA, while $26 \%$ were taking three or more types of OHA. The GH endocrinologists stated that they prescribed insulin combined with OHA or insulin monotherapy significantly more often than the CL internists (40.3\% vs. $21.7 \%$ of their T2DM patients; $P=0.006$ ). Table 1 shows the characteristics of all participants.

\section{Current diabetes education status}

Ninety-eight percent of clinicians reported that they were the diabetes educator for their diabetic patients, and $99 \%$ of the patients responded that they had received diabetes education from their doctor. However, clinicians and patients recalled the delivered education contents and educational situations differently. The majority of clinicians thought that the doctordelivered education had taken place at the time of diagnosis, while most patients reported that they received education at every visit. The focus of patient education appeared to be perceived by both clinicians and patients as the need for adjunctive treatment (diet/exercise) and avoidance of potential complications. Clinicians aimed to explain the necessity for a continuous intake of DM drugs. However, patients did not place a
Table 1. Baseline characteristics of clinicians and patients that participated in the survey

\begin{tabular}{|c|c|c|c|}
\hline Patients $(n=300)$ & No. (\%) & Clinicians $(n=130)$ & No. (\%) \\
\hline Age & & Age & \\
\hline $40-44$ & $60(20)$ & $30-39$ & $16(12)$ \\
\hline $45-49$ & $60(20)$ & $40-49$ & $88(68)$ \\
\hline $50-54$ & $60(20)$ & $50-59$ & $25(18)$ \\
\hline $55-59$ & $60(20)$ & $60+$ & $1(1)$ \\
\hline $60-65$ & $60(20)$ & & \\
\hline Gender & & Gender & \\
\hline Male & $\begin{array}{r}150 / 150 \\
(50)\end{array}$ & Male & $\begin{array}{r}113 / 17 \\
(87)\end{array}$ \\
\hline Area & & Area & \\
\hline $\begin{array}{l}\text { Seoul/Gyeonggi/ } \\
\text { Incheon }\end{array}$ & $180(60)$ & $\begin{array}{l}\text { Seoul/Gyeonggi/ } \\
\text { Incheon }\end{array}$ & $78(60)$ \\
\hline Busan/Gyeongnam & $30(10)$ & Busan/Gyeongnam & $13(10)$ \\
\hline Daegu/Gyeongbuk & $30(10)$ & Daegu/Gyeongbuk & $13(10)$ \\
\hline Gwangju/Honam & $30(10)$ & Gwangju/Honam & $13(10)$ \\
\hline $\begin{array}{l}\text { Daejeon/ } \\
\text { Chungcheong }\end{array}$ & $30(10)$ & $\begin{array}{l}\text { Daejeon/ } \\
\text { Chungcheong }\end{array}$ & $13(10)$ \\
\hline Education level & & T2DM patient load & \\
\hline Less than & $36(12)$ & Low (50-99) & $47(37)$ \\
\hline middle school & & Medium (100-149) & $43(34)$ \\
\hline High school & $180(60)$ & High $(\geq 150)$ & $40(31)$ \\
\hline College and above & $84(28)$ & & \\
\hline
\end{tabular}

Perceived DM severity Specialist certification acquisition

Well controlled

60 (20) Within $10 \mathrm{yr}$

$40(31)$

Intermediately

$39(13)$

11-20 yr ago

70 (54)

controlled

Over 20 yr ago

20 (15)

Poorly controlled $127(42)$

Very poorly $10(3)$

controlled

DK

$64(21)$

\begin{tabular}{lclc} 
Practice setting & \multicolumn{3}{c}{ Practice setting } \\
$\begin{array}{c}\text { GH (included } \\
\text { semiGH) }\end{array}$ & $64(21)$ & GH endocrinologist & $30(23)$ \\
CL (primary care) & $236(79)$ & CL internist & $100(77)$ \\
\hline
\end{tabular}

T2DM, type 2 diabetes; DM, diabetes mellitus; GH, general hospitals; CL, local clinics.

${ }^{a}$ Definition of DM severity: Well controlled, fasting plasma glucose $(\mathrm{FPG}) \leq 125$ or postprandial glucose $(\mathrm{PPG}) \leq 199$; Intermediately controlled, FPG $=126$ to 139 or $P P G=200$ to 249 ; Poorly controlled, $\mathrm{FPG}=140$ to 199 or $\mathrm{PPG}=250$ to 299 ; Very poorly controlled, $\mathrm{FPG}=$ 250 or PPG 250; DK, do not know. 
Table 2. Responses of clinicians and patients for each education type

\begin{tabular}{|c|c|c|c|c|c|c|}
\hline \multirow{2}{*}{ Response } & \multicolumn{2}{|c|}{ Doctor-delivered education } & \multicolumn{2}{|c|}{ Nurse-delivered education } & \multicolumn{2}{|c|}{ Diabetes education program } \\
\hline & Clinicians & Patients & Clinicians & Patients & Clinicians & Patients \\
\hline Education experience & $98(n=127)$ & $99(n=298)$ & $55(n=72)$ & $44(n=131)$ & $40(n=52)$ & $16(n=49)$ \\
\hline \multicolumn{7}{|l|}{ Education situation $^{\mathrm{a}}$} \\
\hline At $\mathrm{DM}$ diagnosis & $69(49)$ & $57(35)$ & $54(33)$ & $58(33)$ & $92(79)$ & \\
\hline At every hospital visit for DM Tx & $74(29)$ & $79(42)$ & $53(19)$ & $45(11)$ & & \\
\hline When glucose level increases & $61(15)$ & $50(17)$ & $40(17)$ & $50(19)$ & $71(2)$ & \\
\hline When patient asks about condition/Tx & $60(5)$ & $33(3)$ & $38(17)$ & $49(24)$ & & \\
\hline When DM drug is changed & $57(1)$ & $23(3)$ & $29(6)$ & $36(11)$ & $44(2)$ & \\
\hline When other disease occurs or get worse & $56(1)$ & 7 & 24 & 5 & $77(17)$ & \\
\hline \multicolumn{7}{|l|}{ Education content $^{\mathrm{a}}$} \\
\hline Need for Tx (diet/exercise) other than drugs & $94(40)$ & $82(41)$ & $61(28)$ & $69(35)$ & 96 & 100 \\
\hline Various complications of DM & $91(24)$ & $82(23)$ & 33 & $56(20)$ & 96 & 71 \\
\hline Importance of continuous drug intake & $76(17)$ & $64(7)$ & $46(11)$ & $51(12)$ & 87 & 53 \\
\hline Importance of $\mathrm{HbAlc}$ management & $83(7)$ & $17(5)$ & $24(1)$ & 10 & 92 & 10 \\
\hline Causes and symptoms of DM & $61(6)$ & $64(12)$ & 25 & $34(8)$ & 88 & 57 \\
\hline Risk and management of hypoglycemia & $78(2)$ & $24(2)$ & $54(10)$ & 14 & 85 & 22 \\
\hline Importance of PPG management & $67(2)$ & $64(2)$ & $32(1)$ & $37(3)$ & 79 & 43 \\
\hline Importance of FPG management & $66(1)$ & $60(2)$ & $33(1)$ & $37(1)$ & 79 & 45 \\
\hline Medication instruction & $97(1)$ & $94(4)$ & $67(7)$ & $85(15)$ & 69 & 27 \\
\hline Need for glucose measure and method & 72 & 72 & $79(3)$ & $70(3)$ & 83 & 31 \\
\hline Insulin injection and self management & 50 & 3 & $58(33)$ & 2 & 79 & 8 \\
\hline Education is helpful $^{\mathrm{a}}$ & & 98 & & 85 & & 88 \\
\hline
\end{tabular}

Duplicate answers are possible. Data are shown as percentage. Numbers in parentheses show percentage as number one priority response among the answers.

DM, diabetes mellitus; Tx, treatment; PPG, postprandial glucose; FPG, fasting plasma glucose.

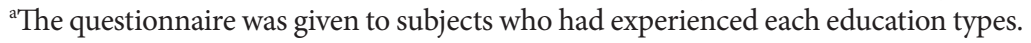

high importance on this issue. Ninety-eight percent of the patients answered that the doctor-delivered education was helpful.

Compared with the responses from the clinicians, the patients responded that they had far less frequent exposure to nurse-delivered education and diabetes education programs (55\% vs. $44 \%, P=0.014$ and $40 \%$ vs. $16 \%, P<0.001$ ). While clinicians perceived that the main content of nurse-delivered education included insulin injection and self-management methods, the patients did not recall this. The majority of clinicians reported that diabetes education programs delivered information on the importance of $\mathrm{HbAlc}$ management, but the patients' recognition of this issue was relatively low ( $92 \%$ vs. $10 \%$ ). Eighty-five percent and $88 \%$ of the patients, respectively, responded that nurse-delivered education and the diabetes edu- cation program were helpful, which was significantly lower than the reported helpfulness of the doctor-delivered education $(P<0.001)$ (Table 2).

A scoring system was used to determine the necessity and sufficiency of each type of education method. A five-point scale was developed for each question. Determination that the question was very necessary/sufficient was given five points, followed by necessary/sufficient (4), neutral (3), not much (2), and not at all (1). A response of more than four points was counted as being 'necessary' and 'sufficient' for each of the survey questions. Doctor-delivered education was considered the most necessary education type by both clinicians and patients. Clinicians scored the necessity of doctor-delivered education and diabetes education programs higher than the patients. While the necessity of diabetes education was highly valued, 
the sufficiency of the current education method was considered to be severely lacking (Table 3 ).

\section{Self monitoring of blood glucose}

Ninety-four percent of clinicians responded that they had recommended SMBG to their patients, but only $78 \%$ of patients could recall having SMBG explained to them, and only $56 \%$ of patients responded that they actually perform SMBG. Patients did not perform SMBG as often as was recommended or at the specific times of day that were recommended by their clinicians. Most clinicians said that they had recommended measuring blood glucose 14 times per week (twice daily) at specific times. Forty percent of patients replied that they currently measured

Table 3. Estimation on necessity and sufficiency of each education type

\begin{tabular}{|c|c|c|c|c|}
\hline \multirow{2}{*}{ Response } & \multicolumn{2}{|c|}{ Education is necessary } & \multicolumn{2}{|c|}{ Education is sufficient } \\
\hline & Score $(95 \% \mathrm{CI})$ & $\%$ & Score $(95 \% \mathrm{CI})$ & $\%$ \\
\hline \multicolumn{5}{|c|}{ Doctor-delivered education } \\
\hline Clinicians & $4.6(4.5-4.8)$ & 96 & $3.4(3.3-3.6)$ & 47 \\
\hline Patients & $4.3(4.2-4.4)$ & 91 & & \\
\hline \multicolumn{5}{|c|}{ Nurse-delivered education } \\
\hline Clinicians & $3.7(3.5-3.9)$ & 60 & $2.8(2.6-3.0)$ & 26 \\
\hline Patients & $3.5(3.4-3.6)$ & 60 & & \\
\hline \multicolumn{5}{|c|}{ Diabetes education program } \\
\hline Clinicians & $3.9(3.7-4.1)$ & 70 & $2.6(2.4-2.8)$ & 24 \\
\hline Patients & $3.5(3.5-3.6)$ & 53 & & \\
\hline
\end{tabular}

CI, confidence interval.

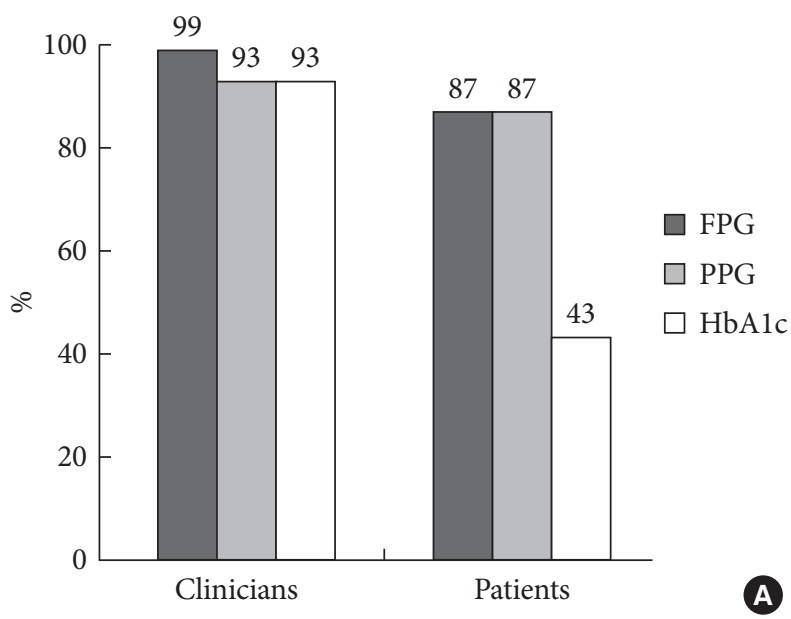

blood glucose level only once per week or even less frequently, and they also reported taking these measurements without any consideration of the timing (data not shown).

\section{Test for diagnosis and treatment of diabetes}

The most used test in the diagnosis and treatment of diabetes was determined by the questions that were asked to the participants. FPG, PPG, and HbAlc levels were all considered to be important diagnostic indicators of diabetes by clinicians, while patients responded that they had performed FPG and PPG measurements more frequently than $\mathrm{HbAlc}$ when they were diagnosed as diabetics $(87 \%, 87 \%$, and $43 \%$ of patients, respectively) (Fig. 1A). Most clinicians said that they considered HbAlc and FPG levels to be a higher priority than PPG in the treatment of T2DM patients $(58 \%, 29 \%$, and $12 \%$ of clinicians, respectively) (Fig. 1B).

\section{Perception of PPG management and achievement of target PPG level}

We questioned whether patients had any knowledge of their target glucose levels. Most patients (84\%) knew their FPG target level, but the majority of patients (93\%) were not aware of their HbAlc target level. While clinicians thought that $50 \%$ of their patients achieved their target glucose level, $72 \%$ of patients thought their glucose was "generally well controlled at the target level." Clinicians who thought that their patients had received sufficient education (regardless of education type) believed that a high percentage of patients were achieving their target glucose level (Table 4).

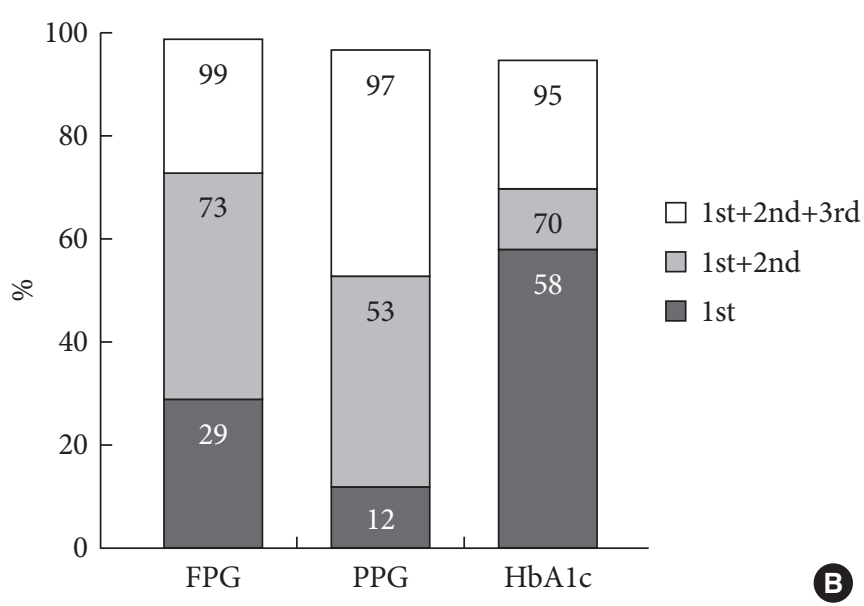

Fig. 1. Usage pattern of check-up test. (A) Test used for diagnosis according to clinicians and patients. (B) Test used for treatment according to clinicians in order of priority. FPG, fasting plasma glucose; PPG, postprandial glucose; HbAlc, glycosylated hemoglobin. 
Table 4. Percentage of patients achieving target glucose level according to education sufficiency as reported by the clinicians

\begin{tabular}{lrcc}
\hline $\begin{array}{l}\text { Education is sufficient } \\
\text { No. }\end{array}$ & $\begin{array}{c}\text { \% of patients achieving } \\
\text { target level }\end{array}$ & $P$ value \\
\hline $\begin{array}{l}\text { Doctor-delivered education } \\
\text { Sufficient }\end{array}$ & 61 & $55.9(50.1-61.7)$ & 0.001 \\
Insufficient & 69 & $44.1(40.0-48.3)$ & \\
$\begin{array}{l}\text { Nurse-delivered education } \\
\text { Sufficient }\end{array}$ & 34 & $60.1(52.6-67.7)$ & 0.001 \\
Insufficient & 96 & $45.9(42.0-49.9)$ & \\
Diabetes education program & & \\
Sufficient & 31 & $57.6(49.8-65.4)$ & 0.015 \\
Insufficient & 99 & $47.2(43.1-51.2)$ & \\
\hline
\end{tabular}

Values are presented as number of subjects and mean (95\% confidence interval).

All patients were aware of the importance of PPG, and most of the patients (89\%) were correctly aware of the desired time to perform the PPG measurement. Most clinicians and patients responded that PPG control was important, but the actual education on PPG was not actively being conducted (Table 5).

\section{DISCUSSION}

This questionnaire-based study found that clinicians are involved in patient diabetes management, as well as patients with diabetes, had acknowledged the importance of diabetes education. In practice, however, health professionals are more likely to simply pass on information rather than to educate their patients. Lack of time, financial constraints, sparse availability of educational tools, and inherent patient passivity are the main reported issues limiting the implementation of patient education into everyday practice [12].

Our study provides insight into the current status of diabetes education. Doctor-delivered education was the most frequent education type reported by both clinicians and patients. However, clinicians and patients perceived the education contents and education situation somewhat differently. We presume that this may be due to clinicians and patients defining the word "education" differently. Clinicians thought that education was related to more in-depth content, while patients recognized more basic topics such as medication instruction as education. There appears to be a significant perception gap between patients and clinicians regarding the implementation of nurse-delivered education and the diabetes education pro-
Table 5. Awareness versus actual education on importance of PPG management

\begin{tabular}{lcc}
\hline Response & Clinicians & Patients \\
\hline PPG management is important & & \\
Very important & 54.6 & 30 \\
Important & 43.1 & 63.3 \\
Similar to other tested levels & 1.5 & 6.3 \\
Not very important & 0.8 & 0.3 \\
Not important & 0 & 0 \\
Frequency of explanation about PPG & & \\
Whenever patients visit & 10 & 20.3 \\
Not every time but frequently & 27.7 & 27 \\
When PPG is not well controlled & 45.4 & 30 \\
Only when PPG get worse & 13.8 & 19 \\
Not at all & 3.1 & 3.7 \\
\hline
\end{tabular}

Values are presented as percentages.

PPG, postprandial glucose.

gram. Patients replied that the helpfulness of nurse-delivered education and of the diabetes education program were significantly lower than that of doctor-delivered education. We note differences in the experiences and helpfulness of each education type based on diabetes treatment setting. Both clinicians and patients perceive doctor-delivered education as being the most helpful compared to other education types. Our survey confirmed that doctor-delivered education was the most effective and powerful means of diabetes management. However, our study also showed that most clinicians thought that doctor-delivered education was insufficient to meet the needs of their patients. In terms of content, education related to SMBG was not as sufficiently or accurately delivered to patients as was thought by the clinicians. There was a significant gap between the doctor-recommended SMBG frequency and the actual measuring frequency performed by the patients.

Clinicians used the HbAlc level as an important target of treatment, but most patients were not aware of their $\mathrm{HbAlc}$ target level. Our findings confirmed observations from previous studies that show patient knowledge of $\mathrm{HbAlc}$ to be relatively poor [13-15]. A recent study has shown that improvements in patient knowledge and understanding of $\mathrm{HbAlc}$ are associated with improvements in glycemic control [16]. PPG level has been found to be a significant contributor to overall glycemic control and to correlate better with $\mathrm{HbA1c}$ level than with FPG in fairly controlled patients [17-19]. However, the 
findings of this study demonstrated that, although the importance of PPG was highly evaluated by both clinicians and patients, education of PPG management was not actively conducted. When targeting PPG, SMBG should be considered since it is currently the most practical method for monitoring PPG [20]. In regard to actual management conditions, the majority of patients replied that they did not perform SMBG nor follow the recommended frequency of SMBG. It seems that this point may act as a barrier for PPG management education. Presently, many epidemiological studies have shown an association between postprandial hyperglycemia and cardiovascular risk. However, data on the beneficial effects of a pharmacological intervention on lowering PPG as determined by cardiovascular end points are scarce in general and non-existent in the case of recently released compounds. We assume that this may explain a doctor's hesitation to administer PPG management education to their patients.

There are several limitations to this study. The major limitation is that surveys based on interviews can yield inaccurate information due to the effects of societal stigmas or perceptions. An additional limitation is that the status of real glucose control and the clinical characteristics of the study participants were not assessed. These limitations should be considered when using our survey results for targeting educational initiatives. Finally, the participants of this study were quota assigned according to age, gender and geographic area. However, we did not perform a stratified analysis. Thus, detailed subgroup analysis should also be performed.

In conclusion, our study showed that there is some discordance in the perception of diabetes education content between clinicians and patients, and there is a considerable gap between awareness and actual education in regard to the importance of PPG. Although the current education for DM patients seems to be well implemented, there are some points that should be improved. More active education is required to help improve the frequency and timing of SMBG and to increase patient knowledge of target glucose level. Promoting the importance of PPG to clinicians also appears to be needed. Our findings emphasize the need for clinicians to more actively educate their patients and encourage the development of proper education programs, especially in regard to PPG management.

\section{CONFLICTS OF INTEREST}

No potential conflict of interest relevant to this article was re- ported.

\section{ACKNOWLEDGMENTS}

This work was supported by research grants from Bayer HealthCare of Korea.

\section{REFERENCES}

1. American Diabetes Association. Standards of medical care in diabetes: 2010. Diabetes Care 2010;33 Suppl 1:S11-61.

2. Boutati EI, Raptis SA. Self-monitoring of blood glucose as part of the integral care of type 2 diabetes. Diabetes Care 2009;32 Suppl 2:S205-10.

3. Nathan DM, Buse JB, Davidson MB, Heine RJ, Holman RR, Sherwin R, Zinman B. Management of hyperglycemia in type 2 diabetes: a consensus algorithm for the initiation and adjustment of therapy: a consensus statement from the American Diabetes Association and the European Association for the Study of Diabetes. Diabetes Care 2006;29:1963-72.

4. Shiraiwa T, Kaneto H, Miyatsuka T, Kato K, Yamamoto K, Kawashima A, Kanda T, Suzuki M, Imano E, Matsuhisa M, Hori M, Yamasaki Y. Post-prandial hyperglycemia is an important predictor of the incidence of diabetic microangiopathy in Japanese type 2 diabetic patients. Biochem Biophys Res Commun 2005;336:339-45.

5. Hanefeld M, Cagatay M, Petrowitsch T, Neuser D, Petzinna D, Rupp M. Acarbose reduces the risk for myocardial infarction in type 2 diabetic patients: meta-analysis of seven long-term studies. Eur Heart J 2004;25:10-6.

6. Hanefeld M, Koehler C, Schaper F, Fuecker K, Henkel E, Temelkova-Kurktschiev T. Postprandial plasma glucose is an independent risk factor for increased carotid intima-media thickness in non-diabetic individuals. Atherosclerosis 1999;144: 229-35.

7. Jackson CA, Yudkin JS, Forrest RD. A comparison of the relationships of the glucose tolerance test and the glycated haemoglobin assay with diabetic vascular disease in the community. The Islington Diabetes Survey. Diabetes Res Clin Pract 1992; 17:111-23

8. DECODE Study Group, on behalf of the European Diabetes Epidemiology Group. Glucose tolerance and cardiovascular mortality: comparison of fasting and 2-hour diagnostic criteria. Arch Intern Med 2001;161:397-405.

9. Donahue RP, Abbott RD, Reed DM, Yano K. Postchallenge 
glucose concentration and coronary heart disease in men of Japanese ancestry. Honolulu Heart Program. Diabetes 1987; 36:689-92.

10. Nakagami T; DECODA Study Group. Hyperglycaemia and mortality from all causes and from cardiovascular disease in five populations of Asian origin. Diabetologia 2004;47:385-94.

11. Nam HW. Training program for diabetes educator. J Korean Diabetes Assoc 1998;22:S49-53.

12. Balcou-Debussche M, Debussche X. Type 2 diabetes patient education in Reunion Island: perceptions and needs of professionals in advance of the initiation of a primary care management network. Diabetes Metab 2008;34(4 Pt 1):375-81.

13. Do DV, Nguyen QD, Bressler NM, Schachat AP, Solomon SD, Melia M, Bressler SB. Hemoglobin Alc awareness among patients receiving eye care at a tertiary ophthalmic center. Am J Ophthalmol 2006;141:951-3.

14. Harwell TS, Dettori N, McDowall JM, Quesenberry K, Priest L, Butcher MK, Flook BN, Helgerson SD, Gohdes D. Do persons with diabetes know their (A1C) number? Diabetes Educ 2002;28:99-105.

15. Heisler M, Piette JD, Spencer M, Kieffer E, Vijan S. The relationship between knowledge of recent $\mathrm{HbAlc}$ values and dia- betes care understanding and self-management. Diabetes Care 2005;28:816-22.

16. Iqbal N, Morgan C, Maksoud H, Idris I. Improving patients' knowledge on the relationship between $\mathrm{HbAlc}$ and mean plasma glucose improves glycaemic control among persons with poorly controlled diabetes. Ann Clin Biochem 2008;45(Pt 5):504-7.

17. Davidson J. Should postprandial glucose be measured and treated to a particular target? Yes. Diabetes Care 2003;26:1919-21.

18. Monnier L, Lapinski H, Colette C. Contributions of fasting and postprandial plasma glucose increments to the overall diurnal hyperglycemia of type 2 diabetic patients: variations with increasing levels of $\mathrm{HbA}(1 \mathrm{c})$. Diabetes Care 2003;26:881-5.

19. Bastyr EJ 3rd, Stuart CA, Brodows RG, Schwartz S, Graf CJ, Zagar A, Robertson KE. Therapy focused on lowering postprandial glucose, not fasting glucose, may be superior for lowering HbA1c. IOEZ Study Group. Diabetes Care 2000;23: 1236-41.

20. Gallwitz B. Implications of postprandial glucose and weight control in people with type 2 diabetes: understanding and implementing the International Diabetes Federation guidelines. Diabetes Care 2009;32 Suppl 2:S322-5. 